\title{
Sexual conflict and speciation
}

\author{
G. A. Parker ${ }^{1}$ and L. Partridge ${ }^{2}$
}

${ }^{1}$ Population Biology Research Group, School of Biological Sciences, University of Liverpool, Liverpool L69 3BX, UK

${ }^{2}$ Galton Laboratory, Department of Biology, University College London, Wolfson House, 4 Stephenson Way, London $\mathcal{N W 1} 2 \mathrm{HE}, \mathrm{UK}$

\begin{abstract}
We review the significance of two forms of sexual conflict (different evolutionary interests of the two sexes) for genetic differentiation of populations and the evolution of reproductive isolation. Conflicting selection on the alleles at a single locus can occur in males and females if the sexes have different optima for a trait, and there are pleiotropic genetic correlations between the sexes for it. There will then be selection for sex limitation and hence sexual dimorphism. This sex limitation could break down in hybrids and reduce their fitness. Pleiotropic genetic correlations between the sexes could also affect the likelihood of mating in interpopulation encounters. Conflict can also occur between (sex-limited) loci that determine behaviour in males and those that determine behaviour in females. Reproductive isolation may occur by rapid coevolution of male trait and female mating preference. This would tend to generate assortative mating on secondary contact, hence promoting speciation. Sexual conflict resulting from sensory exploitation, polyspermy and the cost of mating could result in high levels of interpopulation mating. If females evolve resistance to male pre- and postmating manipulation, males from one population could be more successful with females from the other, because females would have evolved resistance to their own (but not to the allopatric) males. Between-locus sexual conflict could also occur as a result of conflict between males and females of different populations over the production of unfit hybrids. We develop models which show that females are in general selected to resist such matings and males to persist, and this could have a bearing on both the initial level of interpopulation matings and the likelihood that reinforcement will occur. In effect, selection on males usually acts to promote gene flow and to restrict premating isolation, whereas selection on females usually acts in the reverse direction. We review theoretical models relevant to resolution of this conflict. The winning role depends on a balance between the 'value of winning' and 'power' (relating to contest or armament costs): the winning role is likely to correlate with high value of winning and low costs. Sperm-ovum (or sperm-female tract) conflicts (and their plant parallels) are likely to obey the same principles. Males may typically have higher values of winning, but it is difficult to quantify 'power', and females may often be able to resist mating more cheaply than males can force it. We tentatively predict that sexual conflict will typically result in a higher rate of speciation in 'female-win' clades, that females will be responsible for premating isolation through reinforcement, and that 'female-win' populations will be less genetically diverse.
\end{abstract}

Keywords: speciation; sexual conflict; genetic differentiation; reproductive isolation

\section{INTRODUCTION}

We discuss here the role of sexual conflict (or antagonism) - the different evolutionary interests of males and females - as a force regulating the potential for speciation. Although there has been awareness of sexual conflict and its ramifications for many years (e.g. Trivers 1972; Dawkins \& Carlisle 1976; Dawkins \& Krebs 1978, 1979; Parker 1979) there has been relatively little consideration of its possible implications for speciation (but see Parker 1974a, 1979; Wilson \& Hedrick 1982). Our emphasis will be on the evolution of reproductive isolation, because of its central importance in the speciation process. We shall consider the potential role of sexual conflict in the evolution of both pre- and postzygotic isolation.

Conflict between the sexes can occur through two genetic routes (Chapman \& Partridge 1996a). Sexual conflict within gene loci occurs when allelic variation at one locus affects a trait in both males and females, there are different trait optima for the sexes and hence selection for sexual dimorphism. There will then be a genetic correlation between trait values in the two sexes through pleiotropy: effects of the same alleles on males and on females. The difference between selection on the alleles when in females and in males can therefore result in one sex constraining the evolution of the other (Slatkin 1984; Rice 1984; Lande 1987). For instance, high levels of remating in females may be of no direct benefit to females themselves, and may instead occur as a result of a pleiotropic genetic correlation between the sexes for mating frequency, and a correlated response in females to selection for frequent remating in males (Halliday \& Arnold 1987). (In addition, if males mate frequently then, given an equal sex ratio, females must also do so, but this has nothing to do with pleiotropy.) If frequent mating is not merely selectively neutral for females, but positively disadvantageous, perhaps because it incurs physiological costs (Fowler \& Partridge 1989; Chapman et al. 1995), or incresases vulnerability to predators (Rowe 1994; Arnqvist \& Rowe 1995), then the resulting sexual conflict will lead to selection for 
sex limitation, although this may be slow to evolve (Lande 1987). Before the evolution of sex limitation is complete, there will be persistent conflicting selection on alleles at a single gene locus, depending if they are in females or in males.

Sexual antagonism can also arise between alleles at different gene loci when the sexes come into behavioural and physiological conflict, potentially resulting in an arms race, with sequential selection on different male and female traits. There is then antagonistic coevolution among the (sex-limited) gene loci that determine behaviour in males and those that determine behaviour in females (Parker 1979). For instance, sexual harassment and coercion of females by males can result in the evolution of female behavioural and morphological countertactics, such as avoidance of males (Clutton-Brock \& Parker 1995a,b) and defensive abdominal spines (Arnqvist \& Rowe 1995). Antagonistic selection between gene loci is likely to result in an array of behavioural, morphological and physiological sex-limited adaptations that confer benefits on each sex against antagonistic adaptations in the other. Sexual arms races could result in either continuous rapid coevolution at the two sets of gene loci, or in long periods of stasis after attainment of equilibria.

Both types of sexual conflict could have an influence on the evolution of pre- and postzygotic reproductive isolation. The best evidence on the evolutionary progression of these two kinds of barriers to gene flow comes from interspecific crosses in Drosophila (Coyne \& Orr 1989, 1997), where speciation is presumed to be initiated in allopatry. In allopatric species pairs, pre- and postzygotic reproductive isolation evolve at about the same rate, in both cases presumably as an incidental by-product of independent events in the allopatric populations. There are few data from other taxa, but at least one other study suggests that postzygotic isolation accumulates progressively in allopatry (Tilley et al. 1990). Sexual conflict within loci could potentially have two effects. First, sexual dimorphism or sex limitation that has evolved separately in two populations could break down in hybrids, giving rise to postzygotic problems. Second, genetic correlations between the sexes for traits involved in mate choice, and separate evolution in allopatry, could affect the likelihood of interpopulation matings when secondary contact is made. Between-locus sexual conflict could affect the rate of evolution of reproductive isolation in allopatry. Furthermore, it could influence the evolution of postzygotic reproductive isolation in allopatry, if it leads to an arms race and hence rapid divergence of reproductive traits. Between-locus sexual conflict could also play a role in the evolution of premating isolation after secondary contact between populations, and during parapatric and sympatric speciation. In sympatric, but not allopatric, species pairs of Drosophila, prezygotic isolation apparently evolves much more quickly than does postzygotic, providing evidence that partial postzygotic isolation at the time that sympatry resumes may select for reinforcement of mating barriers (Coyne \& Orr 1989, 1997). Theoretical models have shown that selection for mating barriers can also be initiated in both parapatry and sympatry (Lande 1982; Liou \& Price 1994; Kelly \& Noor 1996; Payne \& Krakauer 1997). Differing selection on females and on males for acceptance of matings in interpopulation encounters could produce a role for sexual conflict in determining whether reinforcement of mating barriers does or does not occur.

In this paper we explore the potential role of conflict between the sexes in these various aspects of the speciation process.

\section{WITHIN-LOCUS SEXUAL CONFLICT}

In theory, sexual dimorphism could be achieved by the incorporation into the population of genetic variants that, from the outset, produce sexual dimorphism. There would then be no sexual conflict. However, most new mutations are not completely sex-limited, and it seems likely the evolution of sexual dimorphism often proceeds by the invasion of alleles that produce an advantage only in one sex, followed by the evolution of sex limitation (Rice 1984). Before the evolution of sex limitation the new alleles are sexually antagonistic. Theoretical work has shown that such alleles can invade populations (Rice 1984). For autosomal genes, the disadvantage to one sex must be outweighed by the advantage to the other. In contrast, for sex-linked genes with appropriate dominance relationships, such alleles can invade even when the cost to one sex far exceeds the gain to the other. Specifically, if sex-linked genes coding for the sexually antagonistic trait are dominant and favour the homogametic sex or if they are recessive and favour the heterogametic sex, then they can often invade. Theoretically, alleles producing sex limitation can also then invade (Rice 1984), although the process may be slow (Slatkin 1984; Lande 1987). The extent to which this type of sexual antagonism could have an evolutionary role in speciation will therefore depend in part on the rates at which these processes occur.

Some empiricial evidence suggests that sexually antagonistic alleles are present in natural populations. An artificial selection experiment with Drosophila melanogaster forced visible mutants on the autosomes to pass through only females in each generation. After 29 generations of passage through females, when the resulting mutant chromosomes were introduced to males, they resulted in markedly lowered fitness compared with appropriate controls passaged through both sexes (Rice 1992). However, it was not evident from the results of this experiment whether the alleles affected the same traits in males and in females. Antagonistic effects of the same allele on male and female fitness may be mediated through effects on different characters in the two sexes.

Sexual dimorphism or sex limitation that evolves separately in different populations could break down in hybrids, producing problems with inviability or infertility for either sex. This idea does not seem to have been directly investigated. Some evidence consistent with it comes from the finding that, in introgressions of chromosomal segments between Drosophila simulans and $D$. mauritiana, segments from the $\mathrm{X}$ chromosome had somewhat larger effects than those from autosomes in producing hybrid male sterility (True et al. 1996). This is consistent with an interpretation either of dominant female advantage genes evolving on the $\mathrm{X}$, with the subsequent evolution of sex limitation, which then broke down in the hybrids, or with the presence of recessive X-linked male advantage alleles, which were then incompatible with one another in the hybrids. Assessment of the role of 
genetic correlations between the sexes in this aspect of the speciation process will become more feasible when the identities of more of the genes responsible for postzygotic isolation are known.

Pleiotropic genetic correlations between the sexes could also affect the likelihood of matings in interpopulation encounters. If some male and female reproductive traits are genetically correlated with one another, and therefore evolve together between populations, then the relative likelihoods of intra- and interpopulation matings could be affected. There has been rather little work on this topic, and such data as exist are not strongly supportive of a role for this kind of effect in speciation. In general, it seems unlikely that male and female reproductive traits will be homologous, although characters such as body size certainly are, and can contribute to assortative mating (Arnqvist et al. 1996; Rowe \& Arnqvist 1996). One trait that has received some attention is the willingness of the two sexes to mate (Halliday \& Arnold 1987; Arnold \& Halliday 1988, 1992; Gromko 1992). The few data that exist on this genetic correlation are somewhat conflicting (Stamencovic-Radak et al. 1992), but some data do support the existence of a genetic correlation between male and female mating speeds in Drosophila melanogaster. Artificial selection for mating speed conducted on the two sexes separately showed that the trait was heritable, and indicated a possible genetic correlation between male and female mating speed (Stamencovic-Radak et al. 1992; but, see Stamencovic-Radak et al. 1993; Butlin 1993). However, the indications are that, between different geographic populations of this species, the correlation is the opposite: populations with more vigorous males have more resistant females (van den Berg et al. 1984). The reasons for this correlation are not known. Kaneshiro (1976) has suggested that such a correlation might arise through sexual selection during the founding of new populations, with derived populations in general composed of less vigorous males and less discriminating females, but this theory has found little theoretical or empirical support. In interpopulation matings with $D$. melanogaster, the most probable mating was between more vigorous males and the more receptive females, whereas matings between resistant females and less vigorous males were the least likely (van den Berg et al. 1984). This kind of correlation would therefore result in asymmetrical premating reproductive isolation between populations.

\section{BETWEEN-LOCUS SEXUAL CONFLICT}

\section{(a) Evolution of reproductive isolation in allopatry}

When populations become allopatric, evolution occurs independently in each of the isolates. The likelihood of the populations acting as, or becoming, separate species if there is secondary contact will depend on the degree of pre- and postzygotic isolation that has evolved in allopatry. Very little is known about how postzygotic isolation evolves, because very few genes producing it have yet been identified. Between locus sexual conflict could have a bearing if it led to rapid divergence of reproductive traits. Rapid evolutionary change associated with sexual selection has been suggested to contribute to the increased vulnerability to sterility of male hybrids in Drosophila (Wu \& Davis 1993). Rapid evolutionary divergence would in general be expected to give rise to a higher level of genetic incompatibility when populations meet and attempt to interbreed. But investigation of this interesting possibility is a task for the future.

Premating isolation is likely to evolve in allopatry through a combination of sexual and natural selection, and sexual conflict seems likely to play a role mainly in the former process. Models of the Fisherian process of sexual selection have emphasized the importance of neutral equilibria, random factors and runaway sexual selection of female mating preferences and preferred male traits (Lande 1981; Kirkpatrick 1982). This type of sexual selection could therefore act as fuel for the evolution of premating reproductive isolation. Such divergence through sexual selection could also result in the frequently observed asymmetric premating isolation between populations when secondary contact is resumed (Arnold et al. 1996). It has also been suggested that male reproductive structures that come into physical contact with females, including sperm, show particularly rapid evolutionary change, because female reproductive tracts themselves undergo rapid evolution so as to allow females to make post-copulatory mate choice (see Eberhard (1996) for a review). Recent evidence has shown that postmating, prezygotic events can be important in reproductive isolation in insects (Gregory \& Howard 1994; Price 1997). Whether female choice occurs before or after mating, the Fisherian picture is one of rapid coevolution of male trait and female mating preference. Models of sexual selection based on detectability of male traits or on indicators of male quality also produce population divergence with a positive correlation between male trait and female mating preference for it, but in these cases the male trait shows much greater interpopulation divergence than does the female preference (Schluter \& Price 1993; Price, this volume). Both of these processes would tend, if anything, to lead to assortative mating on secondary contact, and hence to promote speciation, although the importance of this process may have been overemphasized by the Fisherian models of sexual selection (Price, this volume).

A rather different picture of intersexual selection has recently been suggested, which raises the possibility of the involvement of interlocus sexual conflict. Females may be selected to resist frequent mating because they can incur physiological (Fowler \& Partridge 1989; Chapman et al. 1995), or ecological (Rowe 1994; Arnqvist \& Rowe 1995), costs of mating that impair their lifetime reproductive success. Males may then be counter-selected to induce females to mate at a frequency greater than their own optimum (Parker 1979). Sensory exploitation during courtship is one method that could be used by males to persuade the female to mate (West-Eberhard 1984; Dawkins \& Krebs 1978, 1979; Ryan 1990; Kirkpatrick \& Ryan 1991; Endler 1992, 1993; Krakauer \& Johnstone 1995; Rice \& Holland 1998). The male could produce secondary sexual characters with properties that females have been selected to favour in other contexts. Females could then respond by evolving resistance to, rather than preference for, the initially preferred male trait. There is some evidence from phylogenies of male secondary sexual characters and female mating preferences for them that this process may be important in practice. In some phylogenies female preference for male traits are stronger in those species where the male trait has 
apparently never been present than in those where it is present (reviewed in Rice \& Holland 1998). It will be important to determine why we apparently see female resistance evolving in some cases and female preference in others (e.g. Houde \& Endler 1990).

This kind of sexual conflict could continue after insemination has occurred. For instance, sperm-ovum conflict may occur if polyspermy is a problem, leading to an arms race between eggs to resist penetration by sperm and sperm to penetrate as rapidly as possible (reviewed in Rice \& Holland 1998). Males may also resort to molecular coercion, which is potentially costly to females. Female Drosophila melanogaster that remate more frequently suffer an increased death rate and reduced lifetime reproductive success (Fowler \& Partridge 1989). This effect is entirely attributable to the effects of peptides in the seminal fluid of the male (Chapman et al. 1995). These molecules act in the reproductive interests of males by elevating female egglaying rate (Chen et al. 1988), reducing receptivity to future matings (Chen et al. 1988) and removing or disabling the sperm of previous mates of the female (Harshman \& Prout 1994; Chapman et al. 1995; Gilchrist \& Partridge 1997). Female death rate is elevated as a (presumably) unselected side effect. Similar findings have been made for the nematode Caenorhabditis elegans (Gems \& Riddle 1996). Drosophila females can evolve resistance both to male courtship and to the cost of mating. The cost of mating is context-specific; it appears only at levels of nutrition above those that females normally encounter (Chapman \& Partridge 1996b), presumably indicating that females have evolved a mating rate that is not inappropriately high for the conditions that they normally encounter. Female Drosophila prevented from coevolving in response to males, rapidly evolved increased susceptiblity to the cost of mating with those males (Rice 1996), indicating that there must be an arms race between the sexes. Some support for this point of view also comes from the finding that at least some seminal fluid proteins (Acp26Aa and Acp26Ab) show a high evolutionary rate (Aguade et al. 1992; Tsaur \& Wu 1997). However, it should be borne in mind that this rapid evolution could be the result of a sexual arms race between males; some indication of whether these molecules are in evolutionary conflict with the females would be useful.

Sexual conflict resulting from sensory exploitation, polyspermy and the cost of mating could have some complicated effects on populations in secondary contact. If females evolve various forms of resistance to male preand postmating manipulation, then the outcome could depend on the duration of allopatry. At least after short periods of allopatry, males from one population could be more successful with females from the other, because the females would have evolved resistance to their own, but not to the allopatric, males. Males would then at the same time-introduce resistance alleles to the other population, and these would tend to spread because of their advantage to the females. These are not easy ideas to test, but would repay further study. In the longer term, further divergence could lead to prezygotic isolation.

(b) Evolution of premating isolation in secondary contact

When previously allopatric populations resume secondary contact, varying degrees of pre- and postmating isolation may be apparent. Speciation may already be complete if intermating does not occur, or if hybrids are completely inviable or infertile. In contrast, if reproductive isolation is weak, the two populations may simply coalesce. If hybrids are at a disadvantage and there is free mixing of the populations, then extinction of the rarer population is inevitable unless the two populations expoit different resources. Extinction could be avoided if the populations do not mix freely, as a result of only partial overlap or habitat segregation. Further evolution could lead to the formation of a stable hybrid zone. Finally, complete premating isolation between the incipient species may evolve in secondary contact, in other words reinforcement may occur. The plausibility of reinforcement has been the subject of much discussion and some controversy (for reviews, see Butlin 1987, 1995). One problem is that gene flow from the parent populations into the zone of interbreeding could prevent reinforcement of premating barriers. However, two recent models have shown that the process is plausible, both in parapatry and sympatry, if the degree of hybrid disadvantage is sufficently great and the populations are sufficiently diverged in the signals and receptors used in mate recognition (Liou \& Price 1994), or if the genetic architecture of the relevant traits is appropriate (Kelly \& Noor 1996). Ecological differences, in traits such as habitat preference, could also play a role in reducing the frequency of hybridization to a low enough level for reinforcement to occur. Reinforcement is driven by hybrid disadvantage; some degree of postzygotic isolation is required. Under these circumstances, the strength of selection on females and males to avoid forming hybrids may be unequal, leading to sexual conflict over hybridization.

In a given encounter between individuals of opposite sex, there are three possibilities (Parker 1974b, 1979, 1983): (i) it may be in the interests of both sexes to mate; (ii) it may be in the interests of neither sex to mate; (iii) there may be mating conflict, i.e. mating is advantageous for one sex but disadvantageous for the other. Males typically occupy a role in which mating is favourable, and females one in which it is unfavourable; roles may (atypically) be reversed (Parker 1974b, 1979, 1983). We are here concerned with mating conflicts that will affect gene flow between incipient species. We here present mate-foraging models, which provide a description of the selective forces at work. Particularly in the context of speciation, where genetic parameters may also have an important bearing on the evolutionary outcome, the biological relevance of the models should be borne in mind. This point is considered further below.

Parker (1979) proposed a model for sexual conflict over mating decision in which male interests differ from female interests. This analysis relates to disparities between the sexes in terms of reproductive time budgets, with timeout of the mating pool in general greater for females than for males, mainly because of their greater time-investment in offspring. In any encounter between the sexes, the selection on an individual to mate will depend on the expected reproductive gains from the mating and on the average expected gains from rejecting the mating and waiting for other mating opportunities. In general, because the time tied up by the consequences of each mating is greater for females, they lose less by refusing an interpopulation 
mating and waiting for another encounter, because they are likely to encounter another potential mate sooner than are males. The details of the models derived from this approach are presented in Appendix 1. The simplest kind of model (1A) assumes that the two populations have not diverged in traits determining aptitude for encounter, such as population density and mobility, or in amount of time-in and -out of the mating pool for males and females. It is also assumed that interpopulation encounters are relatively rare. Here, unless there is a high male investment time-out, a highly female-biased adult sex ratio, very low encounter rates between the sexes, or hybrid disadvantage is very low, we would commonly expect selection on females to reject hybrid matings. Males, in contrast, would in general be selected to accept them. At the typical state of very low parental investment by males, only very high levels of hybrid disadvantage can generate selection favouring premating isolation in both sexes, and mating conflict will therefore be the rule. Furthermore, even if hybrids between the populations are completely inviable, then there may nonetheless be some sexual conflict over mating. If mate identification is error-prone, then it may sometimes be better for a male to try mating with any female rather than risk missing one of the same population. If the aptitude for encounter, or the relative time-investment in offspring of the sexes, has evolved to different values in the two populations $(i$ and $j)$, similar conclusions will apply, although selection intensity for outcomes is unlikely ever to be symmetric in male $i-$ female $j$ and male $j$-female $i$ meetings. Most plausibly (when male time-out is low and male-female encounters are generally within the same population), there will be sexual conflict favouring male persistence and female rejection in both cases. Less commonly, the hybrid disadvantage may lie in a zone where the selection direction is opposed in the two types of meeting. For example, there may be positive selection for discrimination in say, $j-i$ meetings, but conflict in $i-j$ meetings. If male time-out approaches that of female time-out, it is even possible for there to be an exactly opposite direction of conflict in $i-j$ and $j-i$ meetings. In a more complex model where interpopulation encounters are more common (Appendix 1, model $1 \mathrm{~B}$ ), there is again an extensive zone of conflicting selection on female and male decisions to mate with the other population, with females in general selected to resist and males to attempt to mate.

This consideration of how selection acts on males and females to hybridize or not suggests that males are selected to act as a force for gene flow, whereas females are in general selected to resist it. What are the likely consequences of these selection pressures? If there is any interpopulation mating, and some hybrid viability and fertility, then hybrids will enter the population and reproduce. As they increase in frequency and the range of hybrid genotypes increases, so the pattern of selection on mating decisions will change. Events under these circumstances rapidly become too complex to model. However, models where the populations are already partially isolated by habitat (Liou \& Price 1994) can produce reinforcement, because the potentially swamping effects of gene flow are reduced (model 1B, Appendix 1, can be seen as defining the direction of selection on the two sexes at some balance between within- and between-population matings). In addition, sexual asymmetry in hybrid sterility could be important (Kelly \& Noor 1996). If hybrid males are more affected by sterility than are females, as is generally true with male heterogamety (Haldane's rule), this will tend to promote reinforcement. Futhermore, the empirical evidence from Drosophila supports the occurrence of reinforcement under at least some circumstances (Coyne \& Orr 1989, 1997).

Even without further evolution of antihybridization mechanisms, females may tend to resist interpopulation matings (and males to attempt them) when secondary contact is resumed. When the direction of selection on the two sexes is the same, so that hybridization is in both cases unfavourable, females will often be more strongly selected than are males to resist matings. The same principles will apply when potential mates vary in quality within populations. Females are likely to resist lower-quality partners and males are likely to persist; there will be a zone of conflict over mating decision until a very low mate quality is reached, at which point both sexes will resist, though females will be more strongly selected to do so than males. If evolution in allopatry has resulted in particular mating preferences, then females are likely, in the past, to have been the agents of enforcement, and such mating preferences could lead to assortment for the reasons already discussed. This could help to tip the balance towards reinforcement if females can win the mating conflict, without the need for the evolution of new antihybridization mating behaviour.

The biology of the interaction between the sexes will mediate any effects of sexual conflict on the outcome, both in initial secondary contact and in deciding whether reinforcement will occur. As the evolution of reinforcement is a transitory phenomenon, the evolution of the strategies for winning mating conflict themselves is unlikely to play a major role, but they will have an influence on whether males or females are more likely to win where there is sexual conflict over hybridization. The use of game theory approaches specifically to analyse possible outcomes of conflict over mating decisions began with Parker (1979), and continues to develop (Parker 1983; Clutton-Brock \& Parker 1995a,b) often by reinterpreting other contest models (e.g. Enquist \& Leimar 1983, 1987) in a sexual context. The models search for an evolutionarily stable strategy (ESS; Maynard Smith 1982) solution, and they are therefore not models of 'Red Queen' continuous coevolution in which the strategic possibilities (the rules of the game) are continuously changing. Rather, they assume a possible set of evolutionary options associated with given pay-offs and seek for evolutionarily stable outcomes, as is appropriate in the present context. Both behaviour and morphology will play a role in the resolution of mating conflicts. Behavioural models have generally assumed that there will be asymmetries in armament, which will determine the contest costs. Harassment contests approximate to asymmetric wars of attrition (Maynard Smith 1974; Parker 1979; Hammerstein \& Parker 1982; Clutton-Brock \& Parker 1995a). An important variable in these models is the level or information available to the contestants about relative fighting ability (Maynard Smith \& Parker 1976; Parker \& Rubenstein 1981; Enquist \& Leimar 1983, 1987; Clutton-Brock \& Parker 1995a). In contests where the contestants are 
known to one another, punishment and intimidation, usually of females by males, is a possible ESS (CluttonBrock \& Parker 1995a,b). In addition, the level of armament must itself evolve, which has been examined in theoretical models of an arms race (Parker 1979, 1983; Maynard Smith 1982; Dawkins \& Krebs 1979). Which sex will typically occupy the winning role, i.e. the role with the higher distribution for armament, depends on the difference, for each sex, between the value of winning and between the costs of increasing armaments.

In all these games, the principal determinant of the outcome of mating conflict appears to relate to the balance between:

1. 'Power', or the relative contest costs of the two sexes, e.g. relative cost of enforcing victory for the arms race game, the average relative rates of expenditure of contest cost for the asymmetric war of attrition or sequential assessment game, and the relative ability to inflict damage in the punishment game.

2. 'Value of winning', or the relative fitness difference between mating and not mating (relative opportunity costs), for the two sexes.

In Appendix 2, we build on models $1 \mathrm{~A}$ and $1 \mathrm{~B}$ (Appendix 1) of selection on males and females to avoid or accept hybrid matings, to deduce which sex will have the greater value of winning the mating conflict. With rare encounters between populations, which is the most likely substrate for reinforcement of mating barriers during speciation, there is a large region of the mating conflict where the selection on males to mate is greater than that on females to resist. The reason is that, for most of the parameter space, the difference between the gain to the male from mating with the current female, on one hand, and from continuing to search, on the other, is positive and it is greater than the corresponding gain to the female from continuing to search for a mate of her own population as opposed to accepting the current male. The asymmetry occurs because of the (typically) much longer time a male must spend searching for an alternative mate. When encounters between populations are more frequent, this sex difference in value of winning becomes less marked, but the hybrid disadvantage is also likely to be less because of gene flow, and this will tend to increase the zone of conflict between the sexes. It is also a less plausible scenario for reinforcement. Either way, the odds seem stacked against a female win if only the value of winning is considered.

While the value of winning may generally be loaded in the male interests, power and contest costs in mating conflicts are much less easy to predict. Unless the male is much larger than the female, it may generally be less energetically expensive for a female to prevent mating than for a male to achieve it against female resistance. For example, in most birds, fish, amphibia and other groups in which the males lack a penis, it is difficult to see how a male can mate unless the female cooperates, and even with an intromittent organ, forced copulation may be difficult and costly. If contest costs are greater for the male, this could act to offset the effect of the asymmetry in value of winning, reducing our ability to make predictions about which sex is more likely to occupy the winning role. Thus even where relative armament costs favour the female, this does not necessarily mean that the female must occupy the winning role; persistent harassment by a male is likely to impede females in various deleterious ways. A further complication is that intrasexual selection often drives male body size above that of the female, so that the costs of increasing armaments to males are subsidized by benefits in male-male combat.

Rice \& Holland (1998) discuss gamete conflict over rapid versus slow penetration of sperm into the ovum; sperm favouring fast penetration for competitive reasons, and ova slow penetration to prevent polyspermy. Plant stigmas have long been known to excercise choice of pollen via self-incompatibility (e.g. Baker 1959) and other genotypic features, and recent studies (Bishop et al. 1996) indicate that sperm from other clones can be resisted in the ascidian Diplosoma listerianum. One may speculate about arms races in terms of gamete conflict, in which females are selected to produce ova (or reproductive tracts) with increased resistance to sperm from other populations, and males to produce sperm with increased ability to overcome this resistance. Such arms races would be primarily biochemical. As in mating conflict, the value of winning may be loaded in the male's favour. Perhaps power (contest costs) will be loaded in favour of the female for the following reason. Probably because of sperm competition (Parker 1970), the sperm has tended to become minimal (Parker 1982); any extra armament against the ovum or female tract may be paid for at a loss in sperm numbers or competitiveness. In contrast, the ovum (or female tract) may have resources divertable to the battle at less cost. Thus, whereas male-male competition may have assisted males in the power side of mating conflict, it may have had the opposite effect in gamete conflict. Further, with internal fertilization, gamete conflict occurs within the female, which is also likely to favour female interests in arms races of this type.

In the light of this analysis of outcomes we therefore make three tentative predictions. First - all else equalspeciation will be more extensive in groups where females generally win mating conflicts than in those groups where males usually win. Some evidence supports this prediction, although it has not in general been interpreted in this way. Among passerine birds, net speciation rate (the net outcome of speciation and extinction) is greater in those clades where a higher proportion of the species are sexually dichromatic, presumably indicating a greater role for female mate choice (Barraclough et al. 1995). This correlation would also be predicted by various models of sexual selection that do not involve sexual conflict, and it would be good to have comparative evidence on this point from taxa where intrasexual selection is important. Evidence could consist of some demonstration that those groups where males are typically the bigger sex produce fewer species than those where females are typically bigger or where there is no size dimorphism. Second, and related, where there is evidence for reinforcement, we might predict that it will be the females that are reponsible for the resulting premating isolation. Data are few, but Drosophila provides one example consistent with this prediction. The closely related species $D$. persimilis and $D$. pseudoobscura are sympatric in some locations, and occur singly in others. Rare hybrids between them occur in the field, with the male hybrids sterile. Premating isolation, as 
assayed in behavioural tests, is greater in the areas of sympatry, consistent with the occurrence of reinforcement (Noor 1995). Furthermore, it is the females that are entirely responsible for the premating isolation, males do not discriminate (Noor 1996). Again, it would be nice to have comparative evidence from groups where the power balance between the sexes differs. Third, we predict that in those groups where females tend to win mating conflicts, the genetic variability within each of the many species will be less than within the fewer species in comparable groups where males tend to win. Failure of guppies (Poecilia reticulata) to speciate despite widespread genetic differentiation may well be related to male control (Magurran, this volume). Any empirical evaluation of genetic variation along these lines would need to correct for the effect of population size (having fewer species may generally imply more individuals in each one).

\section{CONCLUSIONS}

Both within- and between-locus sexual conflict may have major roles to play in the progress of the speciation process. Both may affect population divergence in allopatry, and interlocus conflict may be important in determining the outcome of secondary contact, and in promoting parapatric and sympatric speciation. The formulations presented in Appendices 1 and 2 are undoubtedly simplistic: they are phenotypic models in which the pay-offs are constant and related to a fixed hybrid disadvantage, $d$. Despite this limitation, we believe that our general conclusion holds: that in conditions of incipient sympatric or parapatric speciation, or under mixing of populations that have previously diverged allopatrically, females will typically act as a force favouring premating isolation, and males as a force against it.

Rice \& Holland (1998) envisage sexual conflict as fuelling speciation by increasing genetic divergence between populations. Sexual conflict over mate quality within populations is certainly likely to promote genetic divergence between populations with restricted gene flow. Whether it will catalyse or restrict the evolution of mating isolation is likely to depend on the resolution of mating conflict. Mating conflict could be either a hinderance to isolation if 'male-win' scenarios prevail, or a facilitator if females tend to win, with male persistence acting as a major catalyst to speciation by increasing selection on female resitance.

This conflict could, in theory, affect the evolution of any trait involved in the decision whether or not to invest in hybrid offspring. Postmating, prezygotic events, including sperm usage, could be involved, and so could parental investment after fertilization. If there is selection on one sex to avoid fertilization, then it will usually be advantageous to have the barrier as early in the interaction between male and female as possible (reviewed in Eberhard 1996).

Further work is required on more advanced models of the type included here. However, empirical studies are perhaps especially important at this stage, particularly in investigating the propensity for speciation and the extent of genetic diversity in cases where males are likely to be in the winning role in mating conflicts versus those where females are likely to occupy the winning role. Our predic- tion for greater speciosity and less diversity within species in the latter case might be testable in groups with similar ecologies but a wide range of sexual size dimorphism.

We thank Nick Barton, Roger Butlin, Nick Colgrave, Jerry Coyne, Matthew Gage, Mike Ritchie and Tom Tregenza for their thoughtful and constructive input and comments.

\section{APPENDIX 1. CONFLICT BETWEEN THE SEXES OVER HYBRIDIZATION}

For simplicity, we consider time spent on just two forms of reproductive activity: time during which an individual is available for mating and time during which an individual is unavailable for mating (see, also, Clutton-Brock \& Parker 1992; Parker \& Simmons 1996).

Consider a simple case in which each female mates once per reproductive cycle (there are no complexities of 'collateral investment' sensu Parker \& Simmons (1996)). During a given reproductive cycle of duration $T$ time units, a female spends time $S_{\mathrm{f}}$ searching for a mate or otherwise available for mating ('time-in' the mating pool) and time $G_{\mathrm{f}}$ as time unavailable for mate acquisition during parental care, gaining the energy for gametes, etc. ('time-out' of the mating pool). Thus,

$T=S_{\mathrm{f}}+G_{\mathrm{f}}$,

and if the adult sex ratio is $M$ males to each female, then,

$M T=S_{\mathrm{m}}+G_{\mathrm{m}}$,

where times $S_{\mathrm{m}}$ and $G_{\mathrm{m}}$, are the equivalent times 'in' (mate searching time) and 'out' (gamete replenishment, paternal care) for males (see figure 1a). The times out: $G_{\mathrm{f}}$ and $G_{\mathrm{m}}$ are likely to be very different for the two sexes for biological reasons, most notably (but not entirely, see Clutton-Brock \& Parker (1992)) because of the relative difference in parental investment between the sexes (Trivers 1972), which implies (rare sex role reversals excepted) that $G_{\mathrm{f}}>G_{\mathrm{m}}$, and that generally, $G_{\mathrm{f}} \gg G_{\mathrm{m}}$. The average time it will take a receptive female to encounter a male will be inversely proportional to the density of searching males in the same area of the habitat. The searching male density is proportional to $S_{\mathrm{m}} / M T$, the proportion of each adult male's time available for mating. Thus,

$S_{\mathrm{f}}=B M T / S_{\mathrm{m}}$,

$S_{\mathrm{f}}=B M\left(S_{\mathrm{f}}+G_{\mathrm{f}}\right) /\left[M\left(S_{\mathrm{f}}+G_{\mathrm{f}}\right)-G_{\mathrm{m}}\right]$,

where $B$ is a constant related to the 'aptitude for encounter': the lower $B$, the more quickly the sexes meet. To define further, note that if male time-out is negligible compared to time-in (i.e. $S_{\mathrm{m}} \gg G_{\mathrm{m}}$ ), so that the maximum number of adult males is available, $M T / S_{\mathrm{m}} \approx 1.0$, and so $S_{\mathrm{f}} \approx B$. Thus $B$ is the average 'time-in' for a female if all males were to be available all the time in a given population. The solution to the quadratic obtained from the above equation is

$$
\begin{aligned}
S_{\mathrm{f}}= & {\left[-\left(G_{\mathrm{f}}-G_{\mathrm{m}} / M-B\right)\right.} \\
& \left.+\sqrt{\left(G_{\mathrm{f}}-G_{\mathrm{m}} / M-B\right)^{2}+4 B G_{\mathrm{f}}}\right] / 2,
\end{aligned}
$$


(a)

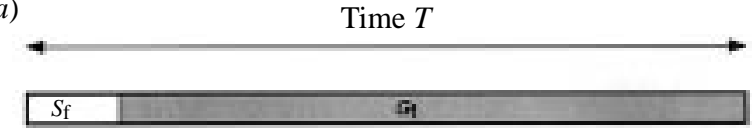

Female
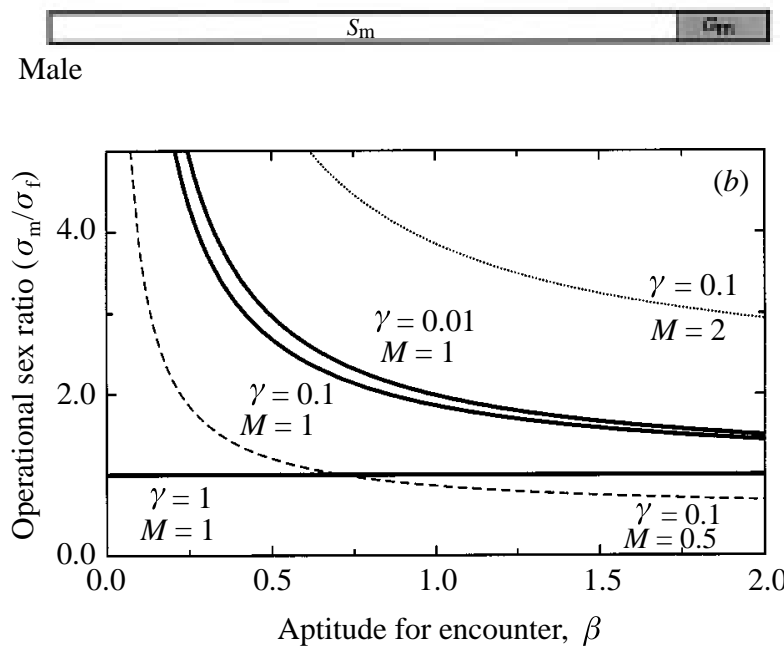

Figure 1. (a) Arrangement of 'time-in' ( $S_{\mathrm{f}}$ for each female and $S_{\mathrm{m}}$ for each male) and 'time-out' ( $G_{\mathrm{f}}$ for each female and $G_{\mathrm{m}}$ for each male) of the mating pool when the adult sex ratio is unity. The 'times-out' are fixed, but the 'times-in' relate to each other as defined in the text. (b) Operational sex ratio, sexually available males divided by sexually available females $\left(\sigma_{\mathrm{m}} / \sigma_{\mathrm{f}}\right)$, calculated from equations $(2 \mathrm{a})$ and $(2 \mathrm{~b})$, plotted against the aptitude for encounter, $\beta$ (see text). The bold curves are for an adult sex ratio (males/females) of $M=1.0$, and show the effect of altering $\gamma$ (the ratio of 'times-out', $\left.G_{\mathrm{m}} / G_{\mathrm{f}}\right)$. The other two curves show the effect of altering adult sex ratio while keeping $\gamma$ constant at 0.1 .

(Clutton-Brock \& Parker 1992). If we set $G_{\mathrm{f}}$ to unity, so that all time periods are expressed relative to the female time-out, we obtain

$$
\begin{aligned}
\sigma_{\mathrm{f}}= & {[-(1-\gamma / M-\beta)} \\
& \left.+\sqrt{(1-\gamma / M-\beta)^{2}+4 \beta}\right] / 2,
\end{aligned}
$$

where $\gamma$ is the male time-out divided by the female timeout (usually $G_{\mathrm{f}}>G_{\mathrm{m}}$, so typically $1>\gamma$ ), $\sigma_{\mathrm{f}}$ is the female time-in scaled by female time-out $\left(\sigma_{\mathrm{f}}=S_{\mathrm{f}} / G_{\mathrm{f}}\right)$, and similarly $\beta=B / G_{\mathrm{f}}$. From equations $(1 a)$ and $(1 b)$, the relative male time-out, $S_{\mathrm{m}} / G_{\mathrm{f}}$ is

$\sigma_{\mathrm{m}}=M\left(\sigma_{\mathrm{f}}+1\right)-\gamma$.

Figure $1 b$ shows the operational sex ratio (OSR, Emlen \& Oring 1977), i.e. the ratio of sexually available males to sexually available females, $\sigma_{\mathrm{f}} / \sigma_{\mathrm{m}}$ (see, also, Clutton-Brock \& Parker 1992) at different vales of relative male 'timeout', $\gamma$, and sex ratio, $M$. At a sex ratio of unity (continuous bold curves), if $\gamma=1$, the sexes are equal and the OSR is 1 , whatever the aptitude for encounter. Reducing $\gamma$ results in highly male-biased OSRs when $\beta$ is low (where the sexual encounter rate is high). If the adult sex ratio is male-biased (upper dotted curve), the OSR is correspondingly higher, and if the adult sex ratio is female-biased (lower broken curve), the OSR is correspondingly lower, and can become female-biased at high values for $\beta$.

\section{(a) Model 1A. Conflict in rare meetings between semi- isolated populations}

We now use the above formulations for $\sigma_{\mathrm{f}}, \sigma_{\mathrm{m}}$, to reapply the logic developed by Parker (1979; which uses less realistic versions of 'times-in') to analyse selection on mating decision conflicts in rare meetings between populations which occasionally meet within the same habitat; there is therefore already a considerable degree of premating isolation. We consider the simple case where there are essentially two semi-isolated populations (figure $2 a$ ). Note that the isolation need not be geographic, it can relate to ecological niches within a habitat, provided that the probability of encounters between opposite sexes of the two populations is low. Imagine initially that the aptitude for encounter, $\beta$, and the ratio of times out for the two sexes, $\gamma$, are similar for the two populations, which have not diverged in these parameters. $\beta$ is likely to be a function of the population densities and relative frequencies of the two populations. We first consider the case where $\beta$ is a fixed property of the populations and interpopulation encounters are rare. We then relax this unrealistic assumption. As there has been some genetic divergence between the two populations, offspring that are hybrids between them have reduced Darwinian fitness relative to the fitness of pure-bred offspring.

Calling this hybrid disvavantage $d$, we deduce the thresholds $d_{\mathrm{m}}, d_{\mathrm{f}}$, which are the threshold levels of hybrid disadvantage for the male and female at which the outcome of mating yields the same fitness as the outcome of not mating. We assume that selection acts to maximize the rate of progeny production (progeny/time) through life. Thus, if a male of one population meets a female of the alternative population, selection favours mating if the gain rate from mating exceeds the gain rate due to searching for a female of the same population, and the threshold is thus given by

$\left(1-d_{\mathrm{m}}\right) / G_{\mathrm{m}}=1 /\left(G_{\mathrm{m}}+S_{\mathrm{m}}\right) ;$

$d_{\mathrm{m}}=\frac{S_{\mathrm{m}}}{G_{\mathrm{m}}+S_{\mathrm{m}}}$; equivalent to $\frac{\sigma_{\mathrm{m}}}{\gamma+\sigma_{\mathrm{m}}} ;$

and by analogy the corresponding decision threshold for a female is

$d_{\mathrm{f}}=\frac{S_{\mathrm{f}}}{G_{\mathrm{f}}+S_{\mathrm{f}}} ;$ equivalent to $\frac{\sigma_{\mathrm{f}}}{1+\sigma_{\mathrm{f}}}$.

Some solutions for the zone of conflict over mating decisions are shown in figures $2 b$ and $2 c$, in which the thresholds $d_{\mathrm{m}}$ and $d_{\mathrm{f}}$ above are plotted against relative male time-out, $\gamma$. In figure $2 b, \beta=0.1$, so that the sexes have a low rate of encounter: with maximum male availability the female must wait on average one-tenth of her investment time (time-out) to find a mate. Given the protracted time-investment by most females to produce a clutch of offspring, this $\beta$ must be regarded as extreme. The bold lines show the thresholds $d_{\mathrm{m}}$ (upper curve) and $d_{\mathrm{f}}$ (lower curve) for the case where the adult sex ratio is unity $(M=1)$. Between these two curves there is mating conflict, with the male under selection to mate and the 
(a)
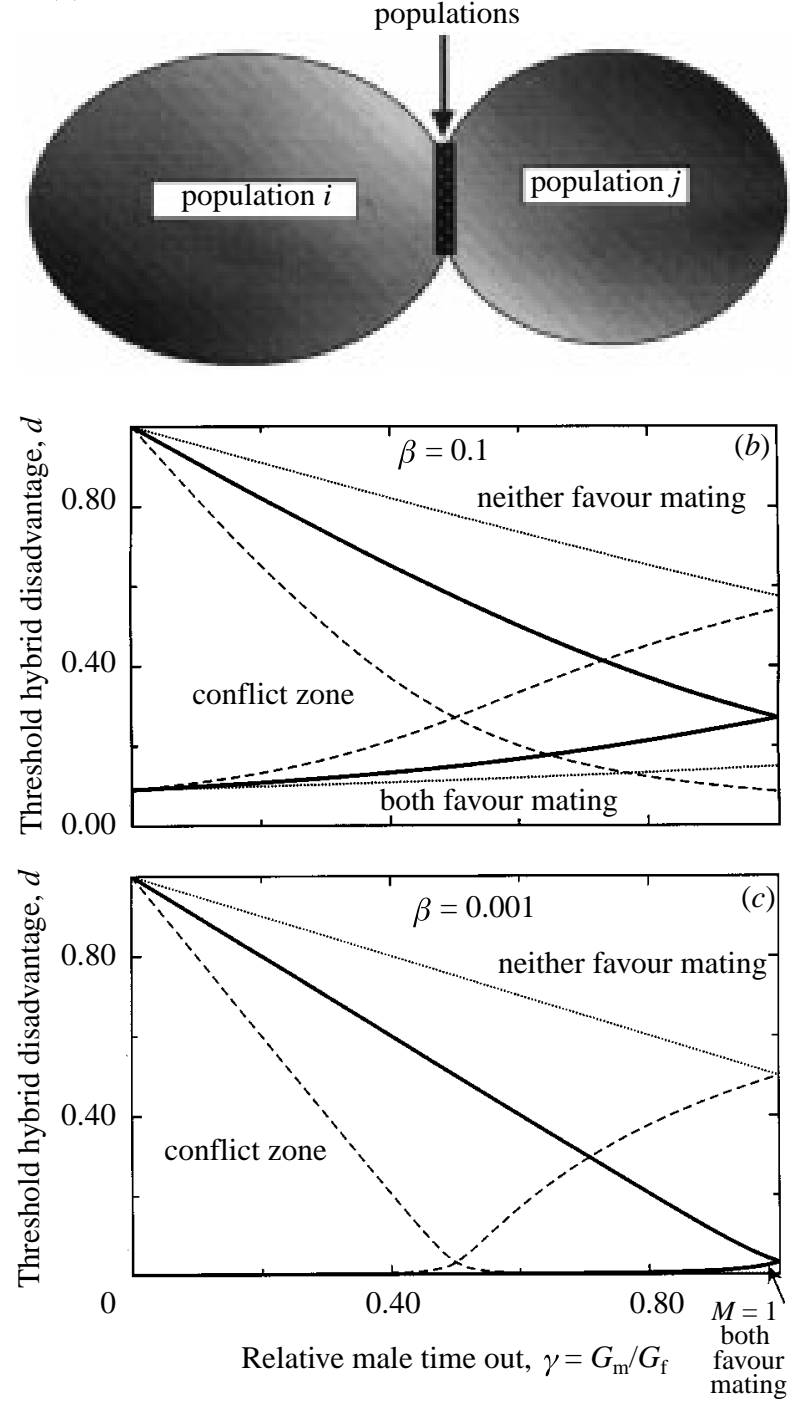

Figure 2. (a) Model 1A, two populations meet only very infrequently at the boundary of their niches, or geographic ranges. (b) Thresholds of hybrid disadvantage in model $1 \mathrm{~A}\left(d_{\mathrm{m}}\right.$ for males, upper curves; and $d_{\mathrm{f}}$ for females, lower curves) at which it pays to switch decision from mating (below curve) to not mating (above curve), plotted against $\gamma$ (the ratio of 'timesout', $\left.G_{\mathrm{m}} / G_{\mathrm{f}}\right)$. Bold curves are for adult sex ratio (males/females) of $M=1.0$; dotted curves are for $M=2.0$; broken curves are for $M=0.5$. Below the female threshold, both sexes favour mating and above the male threshold neither favours mating. Between the two, the sexes are in conflict (see text). The aptitude for encounter is $\beta=0.1$. (c) Same as for $(b)$, but the aptitude for encounter is more typical: $\beta=0.001$.

female under selection to refuse. If the sexes have equal times-out, as might be approached if male and female parental investment is similar, $\gamma=1$, and the sexes have equal thresholds $(d=0.27)$. At the other extreme, $\gamma=0$, and the male has negligible time-out. Then the male should always attempt to mate even if hybrids are almost inviable $(d \rightarrow 0)$; effectively if sperm cost nothing (no timeout costs), any potential offspring are worthwhile. For the female this is not so, and she has a relatively low threshold $(d=0.091)$ of hybrid disadvantage above which she should refuse matings. If the disadavange, $d$, lies above the upper bold curve, neither sex favours mating; if it lies below the lower bold curve, both favour mating. The remaining curves show the corresponding thresholds when the adult sex ratio is $M=2$ (dotted) and $M=0.5$ (broken) males/ female. When the sex ratio is male-biased as $M=2$, even when the sexes are equal in 'times-out' $(\gamma=1)$, the male has a higher threshold because he has a much longer 'time-in' searching for a mate than the female (dotted curves). In contrast, when the adult sex ratio is femalebiased as $M=0.5$, equality of thresholds occurs at $\gamma=0.5$ (broken curves), and for higher values of $\gamma$ the male threshold falls below that of the female so that the conflict zone is inverted (females should persist in courtship of alternative populations and males should reject). Note that such conditions require a high male investment timeout due to mating, or a highly female-biased adult sex ratio. Equality of thresholds occurs only when $\gamma=M$.

A more typical situation would be that females spend a much smaller average time-in awaiting a mating. In figure $2 c$ we examine a case where $\beta=0.001$, so that with maximum male availability each female waits on average one-thousandth of her investment time (time-out) to find a mate. For unity adult sex ratio, the male threshold now drops almost linearly between $\gamma=0$ and $\gamma=1$ (upper bold curve), whereas the female threshold stays close to zero throughout the range (lower bold curve). The female time-in is so short that it pays her to await a meeting with her own population rather than to mate with a male who reduces - even only marginally - the viability of her offspring. The conflict zone is now extensive, and as $\gamma$ increases the zone where neither favour mating increases. The zone where both favour mating is restricted to low values of $d$ at relatively high $\gamma$ (see figure $2 c$ ). When the sex ratio is male-biased as $M=2$ (dotted curves), the female threshold is even more restrictive, being close to zero across the entire range of $\gamma$ from 0 to 1 . The male threshold is now higher, making the conflict zone more extensive. When the sex ratio is female-biased as $M=0.5$ (broken curves), there is again the inversion of conflict for $\gamma>0.5$ (females should persist and males resist).

The above analysis is simplistic in that it assumes that the parameters $\beta$ and $\gamma$ have not diverged for the two populations (see above). A more realistic analysis would take account of such possibilities (see, also, Parker 1979). When these parameters differ, the thresholds $d_{\mathrm{m}}$ and $d_{\mathrm{f}}$ differ for males and females of the two populations. Calling the populations $i$ and $j$, there are two types of rare meeting to consider: (i) male $i \times$ female $j$; (ii) male $j \times$ female $i$. A theoretical possibility would be that there is, say, conflict in case (i) but no conflict in case (ii). The implications of such cases for the probability of evolution of isolation of populations deserve further analysis (see, also, a parallel case in model $1 \mathrm{~B}$, below). However, some properties of models with asymmetric $\beta$ and $\gamma$ can be deduced. Suppose, for example, ecotypes are equal in $\gamma$ but differ in $\beta$ with population $i$ having $\beta=0.1$ and population $j$ having $\beta=0.001$. When a male $i$ meets a female $j$ the conflict zone would lie between the appropriate $d_{\mathrm{m}}$ curve from figure $2 b$, and the appropriate $d_{\mathrm{f}}$ curve from figure 2c. At any given value for $\gamma$, the conflict zone would be increased. In contrast, when a male $j$ meets a female $i$, the conflict zone would lie between the appropriate $d_{\mathrm{m}}$ curve from figure $2 c$, and the appropriate $d_{\mathrm{f}}$ 

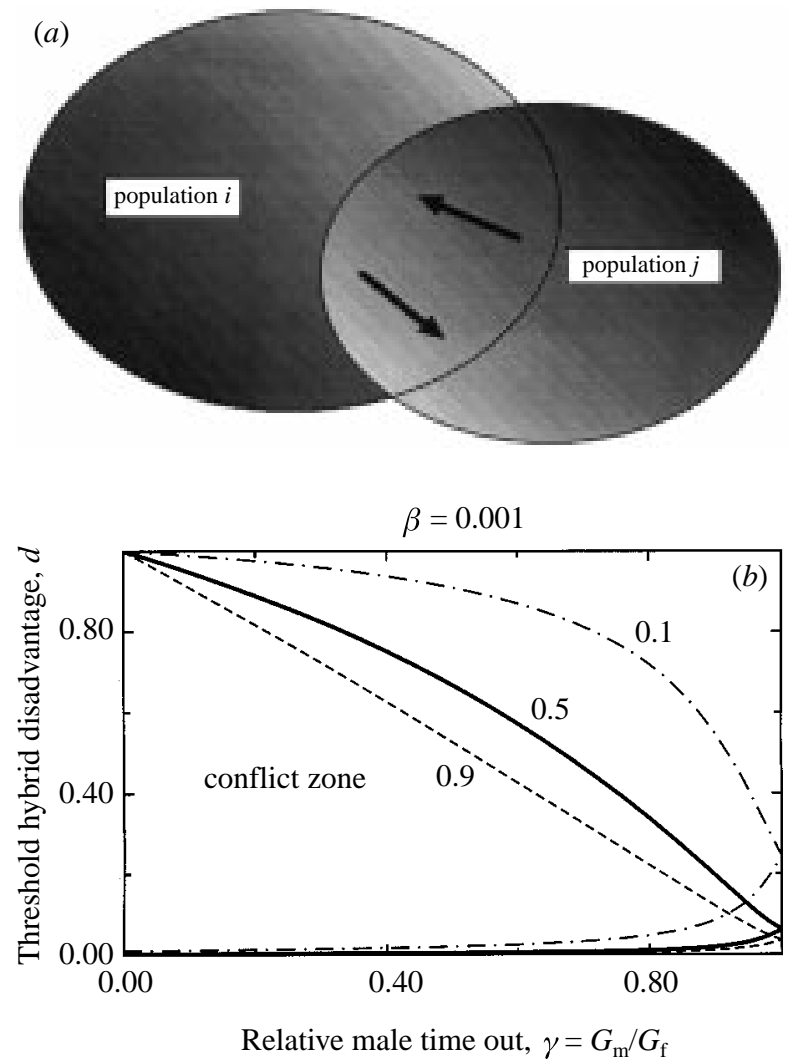

Figure 3. (a) Model 1B, two populations meet frequently in part of the geographic ranges or habitat. (b) Thresholds of hybrid disadvantage in model $1 \mathrm{~B}\left(d_{\mathrm{m}}\right.$ for males, upper curves; and $d_{\mathrm{f}}$ for females, lower curves), at which it pays to switch decision from mating (below curve) to not mating (above curve), plotted against $\gamma$ (the ratio of 'times-out', $G_{\mathrm{m}} / G_{\mathrm{f}}$ ). All curves are for adult sex ratio (males/females) of $M=1.0$. Bold curves are for $p_{i i}$ and $q_{j j}=0.5$; dotted curves are for $p_{i i}$ and $q_{j j}=0.9$; broken curves are for $p_{i i}$ and $q_{j j}=0.1$. Below the female threshold, both sexes favour mating and above the male threshold neither favours mating. Between the two, the sexes are in conflict (see text). The aptitude for encounter is $\beta=0.001$.

curve from figure $2 b$. At low values for $\gamma$, the conflict zone would be reduced, and at high values for $\gamma$, the curves may cross over giving an inversion of conflict so that females persist and males reject.

\section{(b) Model 1B. Conflict over isolation between populations that meet frequently}

In model 1A, encounters with another population were very rare so that search times, $S_{\mathrm{m}}$ and $S_{\mathrm{f}}$, were not significantly affected by cross-population matings. Consider now the situation where two populations commonly meet in part of their ranges or habitats (figure $3 a$ ) where there is no isolation between the two populations. We consider the fate of rare mutations that cause their bearers to mate discriminately (i.e. only with an individual of their own population) rather than indiscriminately. Such mutants increase their search time ('time-in') awaiting a mating, they restrict their mating opportunities to obtain matings of higher value. We again seek thresholds for hybrid disadvantage at which the decision to be discriminate has equal pay-offs to the decision to be indicriminate. The relations for the population for times 'in' and 'out' are as described in equations (1) and (2).
We adopt the following notation: males of population $i$ meet $i$ females with probability $p_{i i}$, and $j$ females with probability $p_{i j}$ (where $p_{i i}+p_{i j}=1$ ); females of population $j$ meet $i$ males with probability $q_{j i}$ and $j$ males with probability $q_{i j}$ (where $q_{j j}+q_{j i}=1$ ). As there is only partial mixing of the two populations, it is generally likely that there is a greater probability of meeting the similar population (i.e. $p_{i i}>p_{i j} ; q_{j j}>q_{j i}$ ), though we shall consider cases where is not so.

Consider a rare mutant male of type $i$ that ignores all females of type $j$. It therefore takes on average time $S_{\mathrm{m}} / p_{i i}$ to encounter a female of its own population $i$, rather than time $S_{\mathrm{m}}$. Its offspring have a fitness of 1.0 relative to an average of $\left[p_{i i}+\left(1-p_{i i}\right)\left(1-d_{\mathrm{m} i}\right)\right]$ for indiscriminate males, in which $d_{\mathrm{m} i}$ is the disadvantage of $i-j$ offspring viewed against $i-i$ offspring. The gain rates of the mutant equals that of indiscriminate males when

$1 /\left(G_{\mathrm{m}}+S_{\mathrm{m}} / p_{i i}\right)=\left[p_{i i}+\left(1-p_{i i}\right)\left(1-d_{\mathrm{m} i}\right)\right] /\left(G_{\mathrm{m}}+S_{\mathrm{m}}\right)$,

which occurs when the hybrid disadvantage is

$d_{\mathrm{m} i}=\frac{S_{\mathrm{m}}}{p_{i i} G_{\mathrm{m}}+S_{\mathrm{m}}}$; equivalent to $\frac{\sigma_{\mathrm{m}}}{p_{i i} \gamma+\sigma_{\mathrm{m}}}$,

when all times are standardized in terms of the female timeout, $G_{\mathrm{f}}$ (see above). To evaluate conflicting selection on mating decision between the sexes, we need to consider the best decision of a female of type $j$, as conflict will concern $i-j$ meetings. A female of type $j$ has a probability of $q_{i j}$ of meeting her own population and $q_{j i}$ of meeting an $i$ male. By a similar analysis we obtain the threshold for $j$ females

$d_{\mathrm{f} j}=\frac{S_{\mathrm{f}}}{q_{j j} G_{\mathrm{f}}+S_{\mathrm{f}}}$; equivalent to $\frac{\sigma_{\mathrm{f}}}{q_{j j} \gamma+\sigma_{\mathrm{f}}}$.

Note that equations $(4 a)$ and $(4 b)$ converge to equations $(3 a)$ and $(3 b)$ for model $1 \mathrm{~A}$ when respectively $p_{i i}$ and $q_{i j}$ approach 1.0 (almost all encounters are within the same population).

We now examine the range of conflict when selection is opposed (mutant $i$ males do best to mate with $j$ females, but $j$ females do best to reject $i$ males). This clearly depends now not only on all the previous time parameters, but also on the relative frequency of the two populations $i$ and $j$. Figure $3 b$ shows the thresholds $d_{\mathrm{m}}$ (upper curves) and $d_{\mathrm{f}}$ (lower curves) for the case where $\beta=0.001$ (potential minimum 'time-in' for the female is one-hundredth of her 'time-out') and where the adult sex ratio is unity $(M=1)$. The bold curves are for the case where $p_{i i}=$ $q_{i j}=0.5$; i.e. where $i$ males meet $i$ and $j$ females equally frequently, and $j$ females meet $i$ and $j$ males equally frequently. The conflict zone between the two curves (where discriminate mating is favoured in females but selected against in males) is extensive and follows a rather similar pattern to that of model $1 \mathrm{~A}$ (cf. bold curves in figure 2c). The broken curves refer to the thresholds when $p_{i i}=q_{i j}=0.9$, where $i$ males meet $i$ females with probability 0.9 and $j$ females with probability 0.1 , and $j$ females meet $j$ males with probability 0.9 and $i$ males with probability 0.1 . This reduces the conflict zone, but not very significantly, because of the strong domination that is exerted on the thresholds by the difference in times-out between the sexes.

Equality in the probability of within-population encounters of the form $p_{i i}=q_{i j}$ is very unlikely. For instance, 
$i$ may overlap over only a small part of its range with $j$, but $j$ may overlap over a large part of its range with $i$, resulting in $p_{i i}>q_{i j}$. The upper dash-dot curve represents the case where $p_{i i}=0.1$, and the lower $q_{i j}=0.1$, i.e. (unlikely) cases where meetings of a given sex occur most commonly with the alternative population. Although it is impossible to envisage this happening concurrently for both populations, it is at least theoretically possible where the two populations have highly asymmetric overlap and occur at different population densities. Then both populations would tend to have higher probability of encounter with the common population. The two sets of curves can then be used to gain some idea of what is happening simultaneously in the two forms of encounter, $i-j$ and $j-i$. For example, males of the rare population meeting females of the common population would tend to have threshold $d_{\mathrm{m}}$ in the zone between the upper bold and dash-dot curves, but females of the common population would tend to have threshold $d_{\mathrm{f}}$ between the lower bold and broken curves. The conflict zone is much more extensive than in meetings between males of the common ecotype $\left(d_{\mathrm{m}}\right.$ now between the upper broken and bold curves) with females of the rare ecotype $\left(d_{\mathrm{f}}\right.$ now between the lower dash-dot and bold curves).

\section{APPENDIX 2. WHICH SEX HAS THE GREATER VALUE OF WINNING THE MATING CONFLICT?}

Call the average costs of one unit of contest time, or the cost of a unit increase in armament $C_{\mathrm{f}}$ for females and $C_{\mathrm{m}}$ for males, and the value of winning $V_{\mathrm{f}}$ for females and $V_{\mathrm{m}}$ for males. A general rule-of-thumb (and a specific prediction for the asymmetric war of attrition, see Parker 1974a; Hammerstein \& Parker 1982) is that sex $i$ is likely to occupy (on average) the winning role defined as $V_{i} / C_{i}>V_{j} / C_{j}$.

We can analyse the models of Appendix 1 above to investigate how the value of winning in mating decision conflicts between populations differs for males and females in relation to relative 'times-out', $\gamma$ (see, also, Parker 1979). The fitness of hybrid progeny is $(1-d)$, where $d$ is the hybrid disdavantage. Suppose that $d$ lies within the conflict zone such that it pays a male to mate but a female not to mate. We calculate the value $V\left(V_{\mathrm{m}}\right.$ for the male, and $V_{\mathrm{f}}$ for the female) as an opportunity cost, the difference between the gain rates achieved by winning and by losing. We then calculate the hybrid disadvantage, $d_{\mathrm{x}}$, at which selection for winning is equal on the two players, i.e. where $V_{\mathrm{m}}=V_{\mathrm{f}}$. By mapping this 'equal selection intensity' threshold on to the plot of conflict thresholds, we can compare the relative areas over which males will be under more intense selection to win than females, and vice versa. Model 2A investigates conditions favouring the benefits of opportunistic indiscriminateness in gaining lower quality progeny at a cost only of the 'time-out' which must be paid for them. Model 2B investigates conditions under which selection favours benefits of discriminateness in gaining better quality progeny at a cost of increased search time ('time-in') this will demand.

\section{(a) Model 2A. Rare encounters between populations}

When a male occasionally meets a female of the alternative population, he achieves a gain rate of $(1-d) / G_{\mathrm{m}}$ if he mates with that female, where $G_{\mathrm{m}}$ is the 'time-out' costs he must pay due to mating (see Appendix 1). If he ignores the female to search for a female of his own population, his gain rate will be reduced to the value $1 /\left(G_{\mathrm{m}}+S_{\mathrm{m}}\right)$, where $S_{\mathrm{m}}$ is the mean search time to find such a female. The female gains are analogous, but we assume that not mating yields the higher gain and examine the condition under which across-population matings are to be avoided. Thus expressing both as positive opportunity costs (mating minus no mating for the male; no mating minus mating for the female):

$V_{\mathrm{m}}=(1-d) / G_{\mathrm{m}}-1 /\left(G_{\mathrm{m}}+S_{\mathrm{m}}\right)$,

$V_{\mathrm{f}}=1 /\left(G_{\mathrm{f}}+S_{\mathrm{f}}\right)-(1-d) / G_{\mathrm{f}}$.

Calling $d_{\mathrm{x}}$ the hybrid disadvantage at which the opportunity costs are exactly equal for the two sexes so that $V_{\mathrm{m}}=V_{\mathrm{f}}$ (i.e. where selection on males favouring mating balances selection on females not to mate), then we can calculate that

$d_{\mathrm{x}}=1-\frac{G_{\mathrm{m}} G_{\mathrm{f}}\left(M^{-1}+1\right)}{\left(G_{\mathrm{m}}+G_{\mathrm{f}}\right)\left(G_{\mathrm{f}}+S_{\mathrm{f}}\right)}$,

(cf. Parker (1979), equation (12) in which the adult sex ratio $M=1$ ). If times are expressed relative to the female 'time-out' cost, $G_{\mathrm{f}}$,

$d_{\mathrm{x}}=1-\frac{\gamma\left(M^{-1}+1\right)}{(1+\gamma)\left(1+\sigma_{\mathrm{f}}\right)}$.

By comparison of equation $(5 b)$ with $d_{\mathrm{m}}$ in equation $(3 a)$, and $d_{\mathrm{f}}$ in equation $(3 b)$, it is possible to show that $d_{\mathrm{m}}>d_{\mathrm{x}}>d_{\mathrm{f}}$ if $\gamma<M$. That is, the hybrid disadvantage below which it pays males to mate $\left(d_{\mathrm{m}}\right)$ is greater than that for equal opportunity costs $\left(d_{\mathrm{x}}\right)$, which is in turn greater than that below which it pays females to mate, provided that the ratio times out $\left(\gamma=G_{\mathrm{m}} / G_{\mathrm{f}}\right)$ is smaller than the ratio of adult males to females $(M)$. If this condition is violated, there is a reversal of sex roles and the inequalities of hybrid disadvantage are reversed (see, also, figures $2 b$ and $2 c$ ).

Figure $4 a$ shows $d_{\mathrm{x}}$ for model 2A (rare meetings between populations) in relation to thresholds $d_{\mathrm{m}}$ and $d_{\mathrm{f}}$ when the aptitude for encounter is $\beta=0.001$, and the adult sex ratio is unity $(M=1.0)$. It clearly lies closer to $d_{\mathrm{m}}$ than $d_{\mathrm{f}}$ unless the relative times out approach equality $(\gamma \rightarrow 1.0)$. To quantify, the relative closeness of $d_{\mathrm{x}}$ to the male threshold $d_{\mathrm{m}}$ can be expressed as

$I=\frac{d_{\mathrm{m}}-d_{\mathrm{x}}}{d_{\mathrm{m}}-d_{\mathrm{f}}}$

i.e. its proportionate deviation from $d_{\mathrm{m}}$ in units of the difference between $d_{\mathrm{m}}$ and $d_{\mathrm{f}}$. Remarkably, for model $2 \mathrm{~A}$ this index is independent of the values of $\beta$ or $M$, and depends only on relative male time-out, $\gamma$. At $\gamma=0, I=0$ and $d_{\mathrm{x}}=d_{\mathrm{m}}$; as $\gamma$ increases, $I$ increases monotonically towards a value of 0.5 (where $d_{\mathrm{x}}$ is equidistant between $d_{\mathrm{m}}$ and $d_{\mathrm{f}}$ ) at $\gamma=1$ (see figure $4 b$ ). Provided that $\gamma<M$, there is no role reversal in sexual conflict so that $d_{\mathrm{m}}>d_{\mathrm{x}}>d_{\mathrm{f}}$, and $d_{\mathrm{x}}$ will be closer to the male threshold. There is a larger region of the conflict zone over which the male experiences more intense selection to mate than the female to reject. In nature, the most typical case is for very small 
relative male time-out $(\gamma \ll M)$. The threshold for equal values of winning lies very close to the male threshold under such circumstances, and the conflict zone is maximal ( $d_{\mathrm{m}}$ approaching 1 , and $d_{\mathrm{f}}$ approaching zero). Most of the rare encounters between males and females of different populations are, therefore, not only likely to involve mating conflict, they are also likely to involve much greater selection pressure on males to win.

\section{(b) Model 2B. Frequent interpopulation encounters}

For frequent meetings, a male of type $i$ mating discriminately (i.e. only with type $i$ females) gains at a rate $1 /\left(G_{\mathrm{m}}+S_{\mathrm{m}} / p_{i i}\right)$, and an $i$ male mating indiscriminately gains at rate $\left[p_{i i}+\left(1-p_{i i}\right)\left(1-d_{\mathrm{m} i}\right)\right] /\left(G_{\mathrm{m}}+S_{\mathrm{m}}\right)$. Assuming that discriminateness is selected against, we subtract the former pay-off from the latter to give $V_{\mathrm{m}}$. Similar relations apply for the female, but reverse the signs of the payoffs to find the condition under which discriminateness is favoured to give $V_{\mathrm{f}}$. Hence

$$
\begin{aligned}
& V_{\mathrm{m}}=\left[p_{i i}+\left(1-p_{i i}\right)\left(1-d_{\mathrm{m} i}\right)\right] /\left(G_{\mathrm{m}}+S_{\mathrm{m}}\right)-1 /\left(G_{\mathrm{m}}+S_{\mathrm{m}} / p_{i i}\right), \\
& V_{\mathrm{f}}=1 /\left(G_{\mathrm{f}}+S_{\mathrm{f}} / q_{j j}\right)-\left[q_{j j}+\left(1-q_{j j}\right)\left(1-d_{\mathrm{f} j}\right)\right] /\left(G_{\mathrm{f}}+S_{\mathrm{f}}\right) .
\end{aligned}
$$

Calling $d_{\mathrm{x}}$ the hybrid disadvantage at $V_{\mathrm{m}}=V_{\mathrm{f}}$, and setting $m=\left(G_{\mathrm{m}}+S_{\mathrm{m}} / p_{i i}\right)$ and $f=\left(G_{\mathrm{f}}+S_{\mathrm{f}} / q_{j j}\right)$, we obtain

$d_{\mathrm{x}}=\frac{M+1-M T\left(m^{-1}+m^{-1}\right)}{\left(1-P_{i i}\right)+M\left(1-q_{j j}\right)}$,

and expressing all times relative to the female 'time-out' cost, $G_{\mathrm{f}}$,

$d_{\mathrm{x}}=\frac{M+1-M\left(1+\sigma_{\mathrm{f}}\right)\left[\left(1+\sigma_{\mathrm{m}} / p_{i i}\right)^{-1}+\left(1+\sigma_{\mathrm{f}} / q_{j j}\right)^{-1}\right]}{\left(1-p_{i i}\right)+M\left(1-q_{j j}\right)}$.

Outcomes of model 2B are illustrated in figures $4 c$ and $4 d$. Figure $4 c$ shows a typical hypothetical case where the probability of encounter of like populations is predominant and equal $\left(p_{i i}=q_{i j}=0.7\right)$, and the adult sex ratio is unity. Threshold $d_{\mathrm{x}}$ for equal values of winning now lies equidistant between $d_{\mathrm{m}}$ and $d_{\mathrm{f}}$ : there is now a much less restricted zone of $d$ over which females may be under more intense selection than in model 2A. Using index $I$, equation (5), to map relative distance of $d_{\mathrm{x}}$ from the male threshold $d_{\mathrm{m}}$, we find that $d_{\mathrm{x}}$ is independent of $\gamma$ and $\beta$ (figure $4 d$ ). For the case where $p_{i i}=q_{i j}, I$ is dependent only on $M$, the adult sex ratio. Where $M=1, d_{\mathrm{x}}$ is equidistant between $d_{\mathrm{m}}$ and $d_{\mathrm{f}}$; increasing $M$ causes $d_{\mathrm{x}}$ to move closer to the female threshold, giving a bigger zone favouring females. Decreasing $M$ has the opposite effect (figure $4 d$ ).

When there is asymmetric overlap between populations $\left(p_{i i} \neq q_{i j}\right), d_{\mathrm{x}}$ is pushed closer to the male threshold in meetings of a rarer male population $i$ with a commoner female $j$; and (simultaneously) towards the female threshold for the commoner males meeting rarer females (figure $4 d$ ). Thus the zone over which males are favoured is greater for the rarer males than for the commoner males, generating asymmetric selection intensity (and possibly also direction) in $i-j$ and $j-i$ meetings.

Although the prospects for females look better under model $2 \mathrm{~B}$, it must be remembered that this is a model essentially of selection for isolation from a prior state of
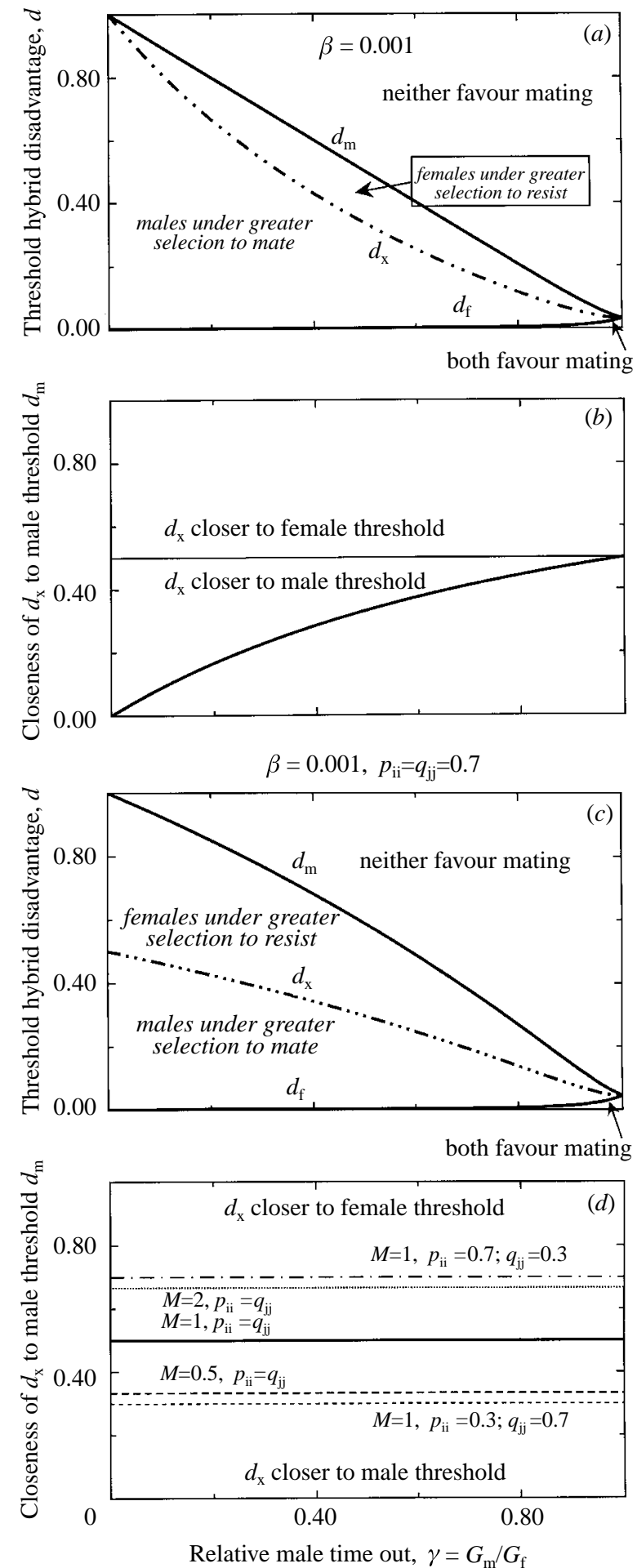

Figure 4. (a) Threshold $d_{\mathrm{x}}$ (dash-dot curve) at which selection on males to mate is equal to selection on females to resist, for model $2 \mathrm{~A}$ in relation to $\gamma$ (the ratio of 'times-out', $G_{\mathrm{m}} / G_{\mathrm{f}}$ ). The upper bold curve is the male threshold, $d_{\mathrm{m}}$, above which males should not attempt to mate and the lower bold curve the equivalent threshold, $d_{\mathrm{f}}$, for the female (see figure $2 c$ ). $\beta=0.001$, and $M=1.0$. Within the conflict zone, at a level of $d$ etween $d_{\mathrm{x}}$ and $d_{\mathrm{m}}$, the female is under greater selection to resist, and between $d_{\mathrm{f}}$ and $d_{\mathrm{x}}$, the male is under greater selection to mate. $(b)$ Plot of index $I$ from equation (6), representing the closeness of threshold $d_{\mathrm{x}}$ to the male threshold $d_{\mathrm{m}}$, for model 2A. (c)

Threshold $d_{\mathrm{x}}$ (dash-dot curve) for model 2B; rest as for $(a)$. $(d)$ Plot of index $I$ from equation (6), representing the closeness of threshold $d_{\mathrm{x}}$ to the male threshold $d_{\mathrm{m}}$, for model 2B; the different values of $p_{i i}, q_{j j}, \beta$ and $M$ are shown against each plot (see text). 
mixing, in which the hybrid disadvantage $d$ is likely to take a low value because of the extensive gene flow between populations. Such conditions of low $d$ favour males (e.g. figure $4 c$ ). When there is effective isolation, with very rare meetings, $d$ may then be much greater, the restricted gene flow allowing much divergence of the two populations. But then the appropriate model is model $2 \mathrm{~A}$, which allows a much greater range over which males are favoured, especially at low relative male time-out.

\section{REFERENCES}

Aguade, M., Myashita, N. \& Langley, C. H. 1992 Polymorphism and divergence in the Mst26A male accessory gland gene region in Drosophila. Genetics 132, 755-770.

Arnold, S. D. \& Halliday, T. R. 1988 Multiple mating: natural selection is not evolution. Anim. Behav. 36, 1547-1548.

Arnold, S. D. \& Halliday, T. R. 1992 Multiple mating by females: the design and interpretation of selection experiments. Anim. Behav. 43, 178-179.

Arnold, S. J., Verrell, P. A. \& Tilley, S. G. 1996 The evolution of asymmetry in sexual isolation: a model and test case. Evolution 50, 1024-1033.

Arnqvist, G. \& Rowe, L. 1995 Sexual conflict and arms races between the sexes: a morphological adaptation for control of mating in a sexual insect. Proc. R. Soc. Lond. B 261, 123-127.

Arnqvist, G., Rowe, L., Krupa, J. J. \& Sih, A. 1996 Assortative mating by size - a meta-analysis of mating patterns in water striders. Evol. Ecol. 10, 265-284.

Baker, H. G. 1959 Reproductive methods as factors in speciation in flowering plants. Cold Spring Harb. Symp. Quant. Biol. 24, 177-191.

Barraclough, T. G., Harvey, P. H. \& Nee, S. 1995 Sexual selection and taxonomic diversity in passerine birds. Proc. R. Soc. Lond. B 259, 211-215.

Bishop, J., Jones, C. S. \& Noble, L. 1996 Female control of paternity in the internally fertilizing compound ascidian Diplosoma listerianum. Proc. R. Soc. Lond. B 263, 401-407.

Butlin, R. K. 1987 Speciation by reinforcement. Trends Ecol. Evol. 2, 8-13.

Butlin, R. K. 1993 A comment on the evidence for a genetic correlation between the sexes in Drosophila melanogaster. Anim. Behav. 45, 403-404.

Butlin, R. K. 1995 Reinforcement: an idea evolving. Trends Ecol. Evol. 10, 432-434.

Chapman, T. \& Partridge, L. 1996a Sexual conflict as fuel for evolution. Nature 381, 189-190.

Chapman, T. \& Partridge, L. $1996 b$ Female fitness in Drosophila melanogaster: an interaction between the effect of nutrition and of encounter rate with males. Proc. R. Soc. Lond. B 263, $755-760$.

Chapman, T., Liddle, L., Kalb, J. M., Wolfner, M. F. \& Partridge, L. 1995 Cost of mating in Drosophila melanogaster females is mediated by male accessory gland products. Nature 373, 241-244.

Chen, P. S., Stumm-Zollinger, E., Aigaki, T., Balmer, J., Bienz, M. \& Bohjlen, P. 1988 A male accessory gland peptide that regulate reproductive behavior of female $D$. melanogaster. Cell 54, 291-298.

Clutton-Brock, T. H. \& Parker, G. A. 1992 Potential reproductive rates and the operation of sexual selection. Q. Rev. Biol. 67, 437-456.

Clutton-Brock, T. H. \& Parker, G. A. $1995 a$ Sexual coercion in animal societies. Anim. Behav. 49, 1345-1365.

Clutton-Brock, T. H. \& Parker, G. A. $1995 b$ Punishment in animal societies. Nature 373, 209-216.
Coyne, J. A. \& Orr, H. A. 1989 Patterns of speciation in Drosophila. Evolution 43, 362-381.

Coyne, J. A. \& Orr, H. A. 1997 'Patterns of speciation in Drosophila' revisited. Evolution 51, 295-303.

Dawkins, R. \& Carlisle, T. R. 1976 Parental investment, mate desertion and a fallacy. Nature 262, 131-133.

Dawkins, R. \& Krebs, J. R. 1978 Animal signals: information or manipulation? In Behavioural ecology: an evolutionary approach (ed. J. R. Krebs \& N. B. Davies), pp. 282-309. Sunderland, MA: Sinauer Associates.

Dawkins, R. \& Krebs, J. R. 1979 Arms races between and within species. Proc. R. Soc. Lond. B 295, 489-511.

Eberhard, W. G. 1996 Female control: sexual selection by cryptic female choice. Princeton University Press.

Endler, J. A. 1992 Signals, signal conditions, and the direction of evolution. Am. Nat. 139, S125-S153.

Endler, J. A. 1993 Some general comments on the evolution and design of animal communication systems. Phil. Trans. R. Soc. Lond. B 340, 215-225.

Enquist, M. \& Leimar, O. 1983 Evolution of fighting behaviour: decision rules and assessment of relative strength. F. Theor. Biol. 102, 387-410.

Enquist, M. \& Leimar, O. 1987 Evolution of fighting behaviour: the effect of variation in resource value. F. Theor. Biol. 127, $187-205$

Fowler, K. \& Partridge, L. 1989 A cost of mating in female fruitflies. Nature 338, 760-761.

Gems, D. \& Riddle, D. L. 1996 Longevity in Caenorhabditis elegans reduced by mating but not by gamete production. Nature 379 , 723-725

Gilchrist, A. S. \& Partridge, L. 1997 Heritability of pre-adult viability differences can explain apparent heritability of sperm displacement ability in Drosophila melanogaster. Proc. $R$. Soc. Lond. B 264, 1271-1275.

Gregory, P. G. \& Howard, D. J. 1994 A postinsemination barrier to fertilisation isolates two closely related ground crickets. Evolution 48, 705-710.

Gromko, M. H. 1992 Genetic correlation of male and female mating frequency: evidence from Drosophila melanogaster. Anim. Behav. 43, 176-177.

Halliday, T. R. \& Arnold, S. J. 1987 Multiple mating by females: a perspective from quantitative genetics. Anim. Behav. 35, 939-941.

Hammerstein, P. \& Parker, G. A. 1982 The asymmetric war of attrition. 7. Theor. Biol. 96, 647-682.

Harshman, L. G. \& Prout, T. 1994 Sperm displacement without sperm transfer in Drosophila melanogaster. Evolution 48, 758-766.

Houde, A. \& Endler, J. 1990 Correlated evolution of female mating preferences and male color pattern in the guppy Poecilia reticulata. Science 248, 1405-1408.

Kaneshiro, K. Y. 1976 Ethological isolation and phylogeny in the plantiba subgroup of Hawaiian Drosophila. Evolution 30, 740-745.

Kelly, J. K. \& Noor, M. A. F. 1996 Speciation by reinforcement: a model derived from studies of Drosophila. Genetics 143, 1485-1497.

Kirkpatrick, M. 1982 Sexual selection and the evolution of female choice. Evolution 36, 1-12.

Kirkpatrick, M. \& Ryan, M. J. 1991 The paradox of the lek and the evolution of mating preferences. Nature 350, 33-38.

Krakauer, D. C. \& Johnstone, R. A. 1995 The evolution of exploitation and honesty in animal communication: a model using artificial neural netoworks. Phil. Trans. R. Soc. Lond. B 348, 355-361.

Lande, R. 1981 Models of speciation by sexual selection on polygenic traits. Proc. Natn. Acad. Sci. USA 78, 3721-3725.

Lande, R. 1982 Rapid origin of sexual isolation and character divergence in a cline. Evolution 36, 213-223. 
Lande, R. 1987 Genetic correlations between the sexes in the evolution of sexual dimorphism and mating preferences. Sexual selection: testing the alternatives (ed. J. Bradbury \& M. B. Andersson), pp. 83-94. Chichester, UK: Wiley.

Liou, L. W. \& Price, T. D. 1994 Speciation by reinforcement of pre-mating isolation. Evolution 48, 1451-1459.

Maynard Smith, J. 1974 The theory of games and the evolution of animal conflicts. F. Theor. Biol. 47, 209-221.

Maynard Smith, J. 1982 Evolution and the theory of games. Cambridge University Press.

Maynard Smith, J. \& Parker, G. A. 1976 The logic of asymmetric contests. Anim. Behav. 24, 159-175.

Noor, M. A. F. 1995 Speciation driven by natural selection in Drosophila. Nature 375, 674-675.

Noor, M. A. F. 1996 Absence of species discrimination in Drosophila pseudoobscura and Drosophila persimilis males. Anim. Behav. 52, 1205-1210.

Parker, G. A. 1970 Sperm competition and its evolutionary consequences in the insects. Biol. Rev. 45, 525-568.

Parker, G. A. 1974a Courtship persistence and female-guarding as male time-investment strategies. Behaviour 48, 157-184.

Parker, G. A. $1974 b$ Assessment strategy and the evolution of fighting behaviour. 7. Theor. Biol. 47, 223-243.

Parker, G. A. 1979 Sexual selection and sexual conflict. In Sexual selection and reproductive competition in insects (ed. M. S. Blum \& N. B. Blum), pp. 123-166. New York: Academic Press.

Parker, G. A. 1982 Why are there so many tiny sperm? Sperm competition and the maintenance of two sexes. F. Theor. Biol. 96, 281-294.

Parker, G. A. 1983 Mate quality and mating decisions. In Mate choice (ed. P. P. G. Bateson), pp. 141-166. Cambridge University Press.

Parker, G. A. \& Rubenstein, D. I. 1981 Role assessment, reserve strategy and acquisition of information in asymmetric animal conflicts. Anim. Behav. 29, 221-240.

Parker, G. A. \& Simmons, L. W. 1996 Parental investment and the control of sexual selection-predicting the direction of sexual competition. Proc. R. Soc. Lond. B 263, 315-321.

Payne, R. J. H. \& Krakauer, D. C. 1997 Sexual selection and speciation. Evolution 51, 1-9.

Price, C. S. C. 1997 Conspecific sperm precedence in Drosophila. Nature 388, 663-666.

Rice, W. R. 1984 Sex chromosomes and the evolution of sexual dimorphism. Evolution 38, 735-742.

Rice, W. R. 1992 Sexually antagonistic genes: experimental evidence. Science 256, 1436-1439.

Rice, W. R. 1996 Sexually antagonistic male adaptation triggered by experimental arrest of female evolution. Nature 381, 232-234.
Rice, W. R. \& Holland, B. 1997 The enemies within: intergenomic conflict, interlocus conflict evolution (ICE), and the intraspecific Red Queen. Behav. Ecol. Sociobiol. 1, 1-10.

Rowe, L. 1994 The costs of mating and mate choice in water striders. Anim. Behav. 48, 1049-1056.

Rowe, L. \& Arnqvist, G. 1996 Analysis of the causal components of assortative mating in water striders. Behav. Ecol. Sociobiol. 38, 279-286.

Ryan, M. J. 1990 Sexual selection, sensory systems and sensory exploitation. Oxf. Surv. Evol. Biol. 7, 156-165.

Schluter, D. \& Price, T. 1993 Honesty, perception and population divergence in sexually selected traits. Proc. R. Soc. Lond. B 253, $117-122$.

Slatkin, M. 1984 Ecological causes of sexual dimorphism. Evolution 38, 622-630.

Stamencovic-Radak, M., Partridge, L. \& Andelkovic, M. 1992 A genetic correlation between the sexes for mating speed in Drosophila melanogaster. Anim. Behav. 43, 389-396.

Stamencovic-Radak, M., Partridge, L. \& Andelkovic, M. 1993 Genetic correlation between the sexes in Drosophila melanogaster: a reply to Butlin. Anim. Behav. 45, 405.

Tilley, S. G., Verrell, P. A. \& Arnold, S. J. 1990 Correspondence between sexual isolation and allozyme differentiation: a test in the salamander Desmgnathus ochrophaeus. Proc. Natn. Acad. Sci. USA 87, 2715-2719.

Trivers, R. L. 1972 Parental investment and sexual selection. Sexual selection and the descent of man (ed. B. Campbell), pp. 136179. London: Heinemann.

True, J. R., Weir, B. S. \& Laurie, C. C. 1996 A genome-wide survey of hybrid incompatibility factors by the introgression of marked segments of Drosophila mauritiana chromosomes into Drosophila simulans. Genetics 142, 819-837.

Tsaur, S. C. \& Wu, G.-I. 1997 Positive selection and the molecular evolution of aa gene of male reproduction, Acp26Aa of Drosophila. Molec. Biol. Evol. 14, 544-549.

van den Berg, M., Thomas, G., Hendriks, H. \& van Delden, W. 1984 A reexamination of the negative assortative mating phenomenon and its underlying mechanism in Drosophila melanogaster. Behav. Genet. 14, 45-61.

West-Eberhard, M. 1984 Sexual selection, competitive communication and species-specific signals in insects. In Insect communication (ed. T. Lewis), pp. 283-324. Toronto: Academic Press.

Wilson, D. S. \& Hedrick, A. 1982 Speciation and the economics of mate choice. Evol. Theory 6, 15-24.

Wu, C.-I. \& Davis, A. W. 1993 Evolution of post-mating reproductive isolation: the composite nature of Haldane's rule and its genetic bases. Am. Nat. 142, 187-212. 